\title{
SISTEM MONITORING KENAIKAN SUHU PADA TRANSFORMER BERBASIS IoT
}

\author{
Moh. Ryadh Dirga Pahlevi ${ }^{1)}$,Ardi Amir ${ }^{2)}$, Tan Suryani ${ }^{3)}$, Muh. Aristo ${ }^{4)}$ \\ ${ }^{1)}$ Program Studi S1 TeknikElektro, FakultasTeknik, UniversitasTadulako \\ ${ }^{2,3,4)}$ Dosen Jurusan Teknik Elektro Universitas Tadulako \\ ${ }^{1)}$ email : Ryadh.dirga.f44116052@gmail.com
}

\begin{abstract}
Transformers play an important role in generating electrical energy so that in maintaining their performance this transformer has a lot of protection so that the transformer can work as much as possible. Many things can interfere with transformers, namely when the transformer is overheated, a short circuit occurs, or is struck by lightning causing the transformer to burn, so a system that can provide fast, and extensive information is needed and is handled automatically by monitoring the temperature of the main transformer using a smartphone connected to the internet network. In this study, 2 DS18B20 sensors were used which were equipped with a Manual Call Point (MCP) as input and an ESP32 microcontroller module in which there was a Wi-Fi module as a data processor, then the output data would be sent via the internet to the Internet of Things (IoT) platform for display. In the form of values, graphs, and notifications. The measurement results are in the form of temperature units in $\mathrm{C}$ which will be displayed via a smartphone using the Blynk IoT platform in the form of numbers and graphs in real-time according to the value detected by the sensor. Tests on sensors resulted in an average error of $3.29 \%$ on the Low side and $3.01 \%$ on the Upside.
\end{abstract}

Keywords: ESP32, DS18B20, Blynk, Internet Of Things, Manual Call Point, Smartphone.

\section{Pendahuluan}

Pembangkit Listrik Tenaga Air (PLTA) merupakan salah satu pembangkit listrik terbarukan yang memanfaatkan aliran air untuk merubah energi gerak ke energi listrik di Sulawesi tengah terdapat PLTA. Dalam sistem pembangkitan listrik dibutuhkan Transformer untuk membangkitkan energi listrik sehingga dapat memiliki energi yang dapat digunakan oleh masyarakat luas.

Transformer berperan penting dalam pembangkitan energi listrik sehingga dalam menjaga performanya transformator ini memiliki banyak proteksi agar transformer dapat bekerja semaksimal mungkin. Banyak hal yang dapat mengganggu transformer yaitu ketika transformer kelebihan panas, terjadi hubung singkat atau tersambar petir sehingga menyebabkan transformer terbakar.

Sistem yang digunakan pada PLTA Poso Peaker 515MW untuk menangani kebakaran pada transformer memiliki teknologi yang hanya mampu menyampaikan informasi di sekitar PLTA melalui suara sehingga penyampaian informasi tidak sampai ke operator yang berada di luar area 
PLTA dan hanya ditangani secara manual jika terjadi kebakaran. Oleh karena itu, diperlukan sistem yang dapat memberikan informasi yang cepat dan luas serta ditangani

\subsection{Sistem Monitoring}

Sistem Monitoring adalah sistem yang sangat diperlukan dalam sebuah aplikasi. Sistem monitoring disini berperan sebagai pemberi data yang nantinya akan diproses lebih lanjut setelah data terkirim dari sebuah sistem monitoring. Sistem monitoring berasal dari bahasa Inggris yaitu "Monitor System" yang dalam bahasa Indonesianya adalah sistem pemantauan. Dalam kehidupan seharihari, sistem pemantauan banyak dilakukan penerapannya dan umumnya dilakukan sebagai bentuk tindakan pencegahan [1].

Sistem monitoring mempunyai dua bentuk konfigurasi data:

1. Konfigurasi data untuk aplikasi monitor itu sendiri.

2. Konfigurasi data untuk sistem yang dipantau.

Aplikasi monitoring membutuhkan informasi path log file dan number of threads untuk menjalankannya. Setelah aplikasi berjalan, perlu untuk diketahui apa yang akan dipantau dan menyimpulkan apa yang telah dipantau. Karena konfigurasi data yang dipantau dibutuhkan di area lain pada sistem, seperti data konfigurasi yang tidak harus dirancang khusus untuk digunakan dalam monitor sistem tetapi harus menjadi model utama dalam sistem utama konfigurasi.

\subsection{Fire Alarm System}

Definisi fire alarm system adalah sistem pendeteksi keberadaan api secara secara otomatis dengan memonitoring suhu transformator utama menggunakan smartphone yang terhubung dengan jaringan internet.

otomatis dengan melihat perubahanperubahan yang terjadi di lingkungan sekitar yang berkaitan dengan kebakaran. Perubahan pada lingkungan sekitar dapat diasumsikan sebagai tanda pendeteksi bahaya kebakaran. Perubahan yang mungkin terjadi misalnya adalah munculnya asap, meningkatnya suhu ruangan, dan munculnya api ataupun gas. Maka dari itu, sebuah fire alarm system selalu dilengkapi dengan sensor yang peka terhadap keberadaan asap, panas, api, maupun gas. Fire alarm system ini dapat dibedakan menjadi dua, yaitu sistem konvensional dan addressable. Sistem konvensional umumnya digunakan pada bangunan yang tidak terlalu besar sedangkan sistem addressable dapat digunakan pada bangunan besar karena sistemnya menggunakan kode digital yang dapat mendeteksi langsung lokasi terjadinya kebakaran pada suatu bangunan.

Dari definisi fire alarm system tadi, diketahui bahwa sistem ini memiliki cara kerja yang berbeda dengan sistem pemadam kebakaran. Kedua sistem ini berdiri secara mandiri. Fire alarm system bukan alat pemadam kebakaran. Tujuan dari fire alarm system ini sendiri adalah untuk menginformasikan kebakaran kepada seluruh penghuni bangunan melalui sistem alarm agar dapat segera mengevakuasi diri dan mengosongkan bangunan. Fire alarm system sangat diwajibkan untuk dipasang pada gedung-gedung penting dan yang bersifat publik seperti rumah sakit, bank, hotel, pusat perbelanjaan dan 
sebagainya. Definisi fire alarm system perlu dipahami agar masyarakat cepat tanggap saat terjadi kebakaran [2].

\subsection{Internet Of Things (IOT)}

Internet of Things (IoT) adalah sebuah konsep di mana suatu objek yang memiliki kemampuan untuk mentransfer data melalui jaringan tanpa memerlukan adanya interaksi dari manusia ke manusia atau dari manusia ke komputer. Internet of Things (IoT) adalah struktur di mana objek, orang disediakan dengan identitas eksklusif dan kemampuan untuk pindah data melalui jaringan tanpa memerlukan dua arah antara manusia ke manusia yaitu sumber ke tujuan atau interaksi manusia ke computer [3].

\subsection{Software Arduino IDE}

Arduino IDE (Integrated Development Enviroment) merupakan perangkat lunak yang telah disiapkan oleh arduino bagi para perancang untuk melakukan berbagai proses yang berkaitan dengan pemrograman arduino. Perangkat lunak disediakan secara gratis dan bisa didapatkan secara langsung pada halaman resmi arduino yang bersifat opensource. IDE ini juga sudah mendukung berbagai sistem operasi popular saat ini seperti Windows, Mac, dan Linux. Pada software IDE ini tidak bisa upgrade secara otomatis, harus secara manual dan kadang pada pembaharuan terbaru ada beberapa library yang di masukkan secara manual, ada yang langsung kompatibel dan sebaliknya [ 4]. Tampilan dari software Arduino IDE ditujukkan pada gambar 1 .

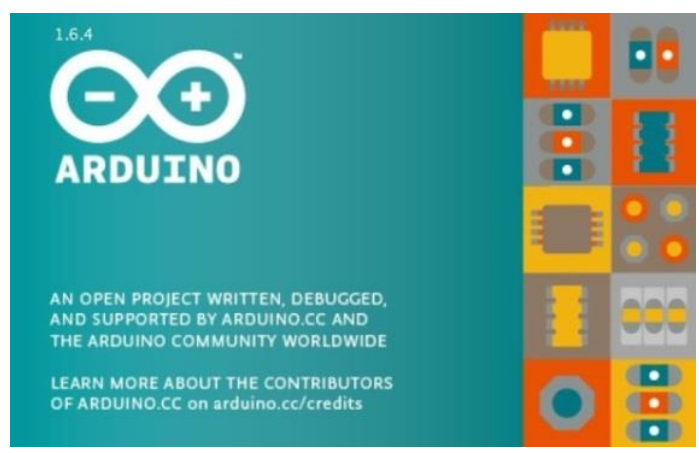

Gambar 1 Software Arduino IDE

(Sumber : Ratna Pratiwi, 2017)

\subsection{Mikrokontroller ESP32}

Mikrokontroler ESP32 adalah perangkat keras berbasis IoT dengan biaya yang cukup murah, sistem daya rendah pada mikrokontroler chip dengan Wi-Fi terintegrasi dan mode ganda Bluetooth. Seri ESP32 menggunakan mikroprosesor Tensilica Xtensa LX6 di kedua dual-core dan single-core variasi dan dilengkapi antena switch, RF balun, power amplifier, low-noise menerima amplifier, filter, dan modul manajemen daya. ESP32 dibuat dan dikembangkan oleh Espressif Systems, perusahaan Cina yang berbasis di Shanghai. Tampilan konfigurasi ESP32 ditunjukan pada gambar 2.

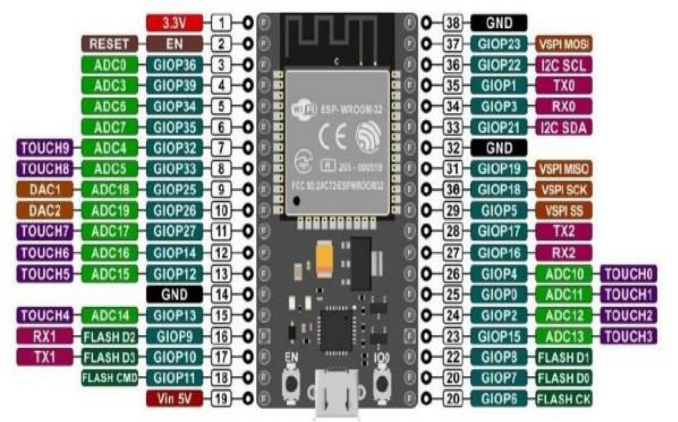

Gambar 2 Konfigurasi Mikrokontroler ESP32

(Sumber : Espressif.com, 2018) 


\subsection{DS18B20}

DS18B20 adalah jenis sensor yang berfungsi untuk mendeteksi suhu ruangan yang merupakan jenis seri sensor terbaru dari keluaran produsen Maxim. Sensor ini dapat mendeteksi suhu dari $-55^{\circ} \mathrm{C}$ sampai $125^{\circ} \mathrm{C}$ dengan tingkat keakurasian $\left(+/-0.5^{\circ} \mathrm{C}\right)$ dan dengan resolusi 9 - 12-bit. Sensor ini merupakan salah satu jenis sensor suhu yang unik. Apabila terdapat banyak sensor yang disusun secara paralel data dari keluaran setiap sensor tersebut dapat dibaca hanya dengan menggunakan 1 kabel data atau (oneWire) saja [5]. Tampilan sensor DS18B20 waterproof di sebelah kiri dan nonwaterproof disebelah kanan ditunjukkan pada gambar 3.
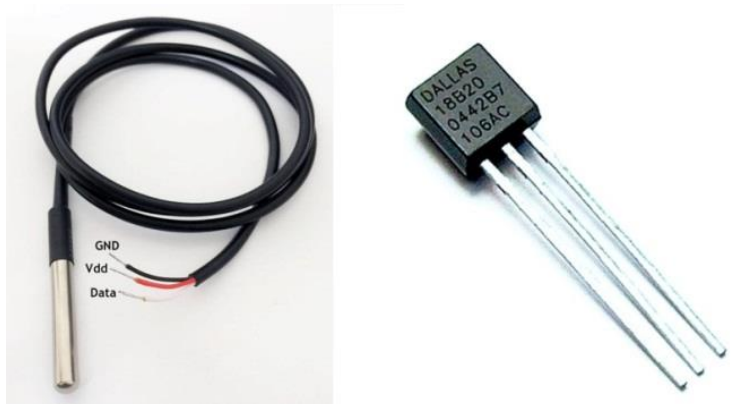

Gambar 3 Sensor DS18B20 waterproof dan non-waterproof

(Sumber : tutorkeren.com, 2020)

\subsection{Manual Call Point (MCP)}

Tombol manual fire alarm, atau kita kenal dengan manual call point. Merupakan salah satu dari komponen rangkaian fire alarm yang memiliki fungsi membunyikan alarm secara manual tanpa menunggu detektor terpicu. Hal ini dilakukan jika kita melihat adanya kebakaran yang belum begitu besar. Sehingga orang-orang di dalam gedung dapat mengevakuasi diri. Pihak berwenang juga dapat langsung mengambil tindakan berupa pemadaman menggunakan fire

hydrant maupun APAR (jika memang kebakarannya kecil dan belum membesar).

Fungsi dari kaca pada manual call point tersebut dilakukan guna melindungi tombol ditekan oleh orang iseng yang tidak bertanggung jawab. Hal tersebut juga melindungi tombol rusak akibat pengaruh lingkungan [6]. Tampilan manual call point ditunjukkan pada gambar 4 .

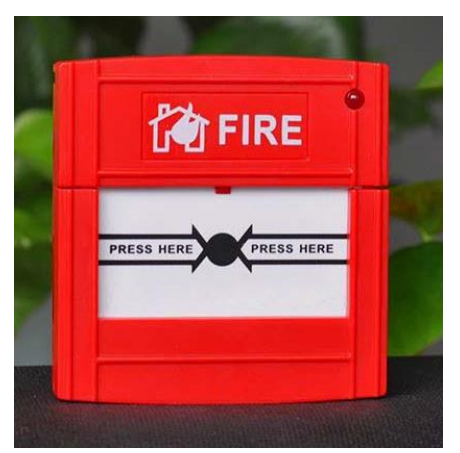

Gambar 4 Manual call point

(Sumber: bromindo.com, 2020)

\subsection{Sirine}

Sirene adalah alat untuk membuat suara. Sirene berfungsi untuk memperingatkan masyarakat akan bahaya suatu bencana alam dan digunakan untuk kendaraan layanan darurat seperti ambulans, polisi, dan pemadam kebakaran. Bentuk sirene yang paling modern adalah sirene serangan udara, sirene tornado, sirene tsunami dan sirene untuk kendaraan layanan darurat. Untuk sirene pemadam kebakaran biasanya juga digunakan sebagai sirene tornado. Suara dari sirene dahulu kala diproduksi di bawah air karena dihubungkan 
dengan Siren dari mitologi Yunani. Kini sirene digunakan untuk pos penjagaan dan peringatan akan serangan udara. Sirene secara umum ada dua jenis yaitu Pneumatik dan Elektronik.

Sirine biasanya diletakkan di tempat yang tinggi di atas atap atau di sisi samping pos pemadam kebakaran, di atas struktur bangunan tinggi seperti menara air, ditempatkan dekat gedung pemerintahan, di tempat-tempat strategis di lingkungan masyarakat, atau ditempatkan didekat lingkungan masyarakat agar suara peringatan bisa tercakupi untuk semua area. Kebanyakan sirene hanya memiliki satu jenis nada atau suara. Melihat cara kerja sirene, secara mekanis sirene digerakkan oleh sebuah motor elektrik dengan rotor terpasang pada shaft. Beberapa Sirene versi terbaru secara elektronik digerakkan oleh pengeras suara. Walau begitu versi sirene seperti ini bukanlah versi yang umumnya ada. Sirene memiliki banyak tipe [6].

\subsection{Blynk}

Blynk adalah aplikasi untuk iOS dan OS Android untuk mengontrol Arduino, NodeMCU, Raspberry Pi dan sejenisnya melalui Internet. Aplikasi ini dapat digunakan untuk mengendalikan perangkat hardware, menampilkan data sensor, menyimpan data, visualisasi, dan lain-lain. Aplikasi Blynk memiliki 3 komponen utama.yaitu Aplikasi, Server, dan Libraries. Blynk server berfungsi untuk menangani semua komunikasi diantara smartphone dan hardware. Widget yang tersedia pada Blynk diantaranya adalah Button, Value Display, History Graph, Twitter, dan Email.
Blynk Aplikasi adalah aplikasi dengan user diberi kebebasan untuk membuat sebuah tampilan antarmuka menggunakan berbagai macam widget yang tersedia. Pada Blynk app terdapat empat kategori widget yaitu Controllers, Displays, dan Notifications [7]. Tampilan aplikasi blynk ditunjukkan pada gambar 2.5.

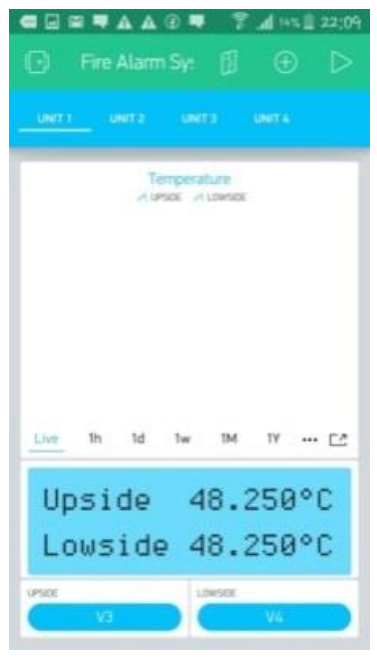

Gambar 5 Tampilan Aplikasi Blynk

\section{Metode Penelitian}

\subsection{Alat dan Bahan Penelitian}

Dalam penyusunan dan pembuatan skripsi ini, menggunakan beberapa macam alat dan bahan yang diuraikan pada sub bab di bawah ini:

\subsubsection{Bahan Penelitian}

Bahan yang digunakan pada penelitian ini yaitu sensor sensor suhu DS18B20, Manual call point, media panas. Mikrokontroler Esp32 dan Platform IoT yaitu Blynk. 


\subsubsection{Alat Penelitian}

Adapun alat-alat yang digunakan pada penelitian ini antara lain perangkat lunak (software) Arduino IDE sebagai media pemrosesan data, smartphone sebagai penerima dan server pendukung tampilan data.

\subsection{Cara Penelitian}

Metode yang digunakan dalam penelitian ini adalah metode kualitatif berbasis eksperimen. Rancangan tahap-tahap dari penelitian ini dibutuhkan agar penelitian yang dilakukan terstruktur dan sesuai dengan rencana. Penulis membuat sebuah prototipe Sistem Monitoring Kenaikan Suhu Pada Transformer berbasis IoT yang diharapkan dapat memonitoring suhu transformer dan menginformasikan kenaikan suhu secara jarak jauh dan real time.

\section{Hasil dan Pembahasan}

\subsection{Hasil Penelitian}

Dari hasil perancangan dan penelitian yang berjudul sistem monitoring kenaikan suhu pada transformer Berbasis IoT, maka penulis dapat menampilkan dalam bentuk alat, software, data, maupun analisa data. Berikut hasil perancangan dan penelitian yang telah penulis lakukan.

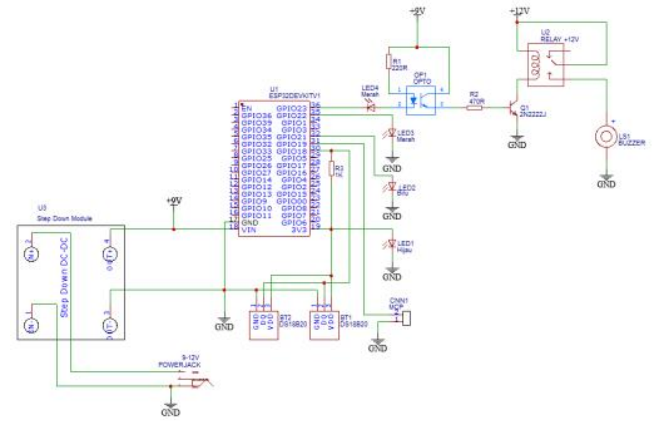

\section{Gambar 6 Skematik Rangkaian}

\subsection{Pengujian Alat}

Pengujian sensor DS18B20 dilakukan untuk mengetahui apakah sensor ini bekerja dengan baik serta dapat mendeteksi suhu dengan benar, jika sensor tidak dapat bekerja maka nilai suhu yang terbaca adalah $-127^{\circ} \mathrm{C}$. Dimana kedua sensor pin datanya di hubungkan pada pin GPIO18 ESP32 untu pin vec dihungkan ke sumber tegangan 3.3V serta GND pada ground Seperti pada gambar. Pengujian dilakukan dengan memanaskan sensor menggunakan media pemanas secara bertahap, berikut gambaran data output sensor yang ditampilkan pada serial monitor arduino IDE. Kemudian data setiap output sensor pada arduino IDE akan dibandingkan menggunakan termometer sebagai pengujian tingkat akurasi sensor seperti terlihat pada tabel 4.1 dan tabel 4.2

Tabel 4.1 Pengujian Akurasi sensor pada Low Side

\begin{tabular}{|c|c|c|c|c|}
\hline \multirow{2}{*}{ No } & \multirow{2}{*}{$\begin{array}{c}\text { Suhu } \\
\text { Pengujian } \\
\left({ }^{\circ} \mathrm{C}\right)\end{array}$} & $\begin{array}{c}\text { Sensor } \\
\left({ }^{\circ} \mathrm{C}\right)\end{array}$ & \multirow{2}{*}{$\begin{array}{l}\text { Alat } \\
\text { Ukur } \\
\left({ }^{\circ} \mathrm{C}\right)\end{array}$} & \multirow{2}{*}{ error $(\%)$} \\
\hline & & $\begin{array}{l}\text { Low } \\
\text { Side }\end{array}$ & & \\
\hline 1 & 40 & 40.5 & 40 & 1.23 \\
\hline 2 & 50 & 50.25 & 49 & 2.48 \\
\hline 3 & 60 & 60.25 & 59 & 2.07 \\
\hline 4 & 70 & 70 & 69 & 1.42 \\
\hline 5 & 80 & 80.5 & 77 & 4.34 \\
\hline 6 & 90 & 91 & 84 & 7.69 \\
\hline 7 & 100 & 98.75 & 95 & 3.79 \\
\hline \multicolumn{4}{|c|}{ Rata-rata } & 3.29 \\
\hline
\end{tabular}

Tabel 4.2 Pengujian Akurasi sensor pada Up Side 


\begin{tabular}{|c|c|c|c|c|}
\hline \multirow{2}{*}{ No } & \multirow{2}{*}{$\begin{array}{c}\text { Suhu } \\
\text { Pengujian } \\
\left({ }^{\circ} \mathrm{C}\right)\end{array}$} & $\begin{array}{c}\text { Sensor } \\
\left({ }^{\circ} \mathrm{C}\right)\end{array}$ & \multirow{2}{*}{$\begin{array}{l}\text { Alat } \\
\text { Ukur } \\
\left({ }^{\circ} \mathrm{C}\right)\end{array}$} & \multirow{2}{*}{ error $(\%)$} \\
\hline & & $\begin{array}{c}\text { Up } \\
\text { Side }\end{array}$ & & \\
\hline 1 & 40 & 40.25 & 40 & 0.62 \\
\hline 2 & 50 & 50 & 49 & 2 \\
\hline 3 & 60 & 60 & 59 & 1.66 \\
\hline 4 & 70 & 70 & 69 & 1.42 \\
\hline 5 & 80 & 80.75 & 77 & 4.64 \\
\hline 6 & 90 & 91 & 84 & 7.69 \\
\hline 7 & 100 & 98 & 95 & 3.06 \\
\hline \multicolumn{4}{|c|}{ Rata-rata } & 3.01 \\
\hline
\end{tabular}

Perbandingan nilai data sensor suhu DS18B20 pada platform Blynk dan termometer dengan melakukan percobaan sebanyak 7 kali dengan 4 level dalam rentang waktu yang berbeda, hal ini dilakukan untuk melihat tingkat akurasi sensor.

Perhitungan nilai error dilakukan dengan rumus mencari nilai persen error sebagai berikut :

$$
\text { Error }=\llbracket \frac{\mathbf{a}-\mathbf{b}}{\mathbf{a}} \rrbracket \times 100 \% \ldots \ldots
$$

Keterangan:

$\mathrm{a}=$ Data sensor DS18B20

$\mathrm{b}=$ Termometer

Perhitungan dengan mengambil salah satu sampel data pada table 4.2 Pengujian ke1 pada Level aman berdasarkan rumus mencari nilai persen error :

Diketahui : $\mathrm{a}=40.25, \mathrm{~b}=40$;

Ditanya : Nilai Persen Error ?

Penyelesaian :

$$
\begin{aligned}
& \text { Error }=\llbracket \frac{\mathbf{a}-\mathbf{b}}{\mathbf{a}} \rrbracket \times 100 \% \\
& =\llbracket \frac{\mathbf{4 0 . 2 5 - 4 0}}{\mathbf{4 0 . 2 5}} \rrbracket \times 100 \%=0.62 \%
\end{aligned}
$$

Jadi, didapatkan nilai persen error data pada table 4.2 pengujian ke- 1 pada level aman sebesar 0,62 \%. Nilai tersebut dijumlahkan dengan nilai error yang lainnya kemudian dibagi dengan jumlah data yang ada sehingga mendapatkan nilai rata-rata error sebesar $3.01 \%$

Pengujian ini dilakukan dengan tujuan untuk mengetahui apakah alat yang telah dibuat berfungsi sesuai dengan sistem yang direncanakan atau belum. Pada penelitian ini dilakukan percobaan sebanyak 7 kali pada kedua sensor dengan tingkatan suhu yang berbeda. Hal ini dilakukan untuk melihat tingkat keberhasilan sensor untuk mendeteksi serta pengirman data ke platform Blynk secara wireless maupun tingkat keberhasilan sistem secara keseluruhan.Untuk MCP dilakukan pengujian dengan cara ditekan Berikut data hasil pengujian alat, di tunjukkan pada tabel 4.3 sedangkan pada

\begin{tabular}{|c|c|c|c|c|c|c|c|}
\hline \multirow{2}{*}{ No } & \multirow{2}{*}{ 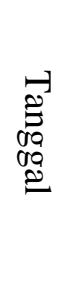 } & \multirow{2}{*}{ 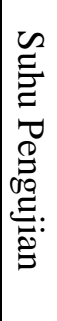 } & \multicolumn{2}{|c|}{ ○ी } & \multirow{2}{*}{ 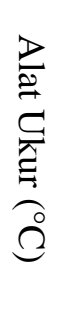 } & \multirow{2}{*}{ 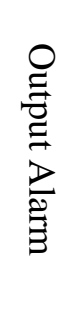 } & \multirow{2}{*}{ 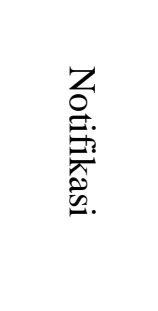 } \\
\hline & & & 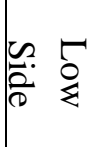 & $\begin{array}{l}\overparen{C} \\
\tilde{\sigma} \\
\frac{2}{0}\end{array}$ & & & \\
\hline 1 & $\begin{array}{c}8-3- \\
202 \\
1\end{array}$ & $\begin{array}{l}4 \\
0\end{array}$ & $\begin{array}{c}40 . \\
5\end{array}$ & $\begin{array}{c}40 . \\
25\end{array}$ & 40 & Off & Normal \\
\hline 2 & $\begin{array}{c}8-3- \\
202 \\
1\end{array}$ & $\begin{array}{l}5 \\
0\end{array}$ & $\begin{array}{l}50 . \\
25\end{array}$ & 50 & 49 & Off & Normal \\
\hline 3 & $\begin{array}{c}8-3- \\
202 \\
1\end{array}$ & $\begin{array}{l}6 \\
0\end{array}$ & $\begin{array}{c}60 . \\
25\end{array}$ & 60 & 59 & Off & Waspada \\
\hline 4 & $\begin{array}{l}8-3- \\
202\end{array}$ & $\begin{array}{l}7 \\
0\end{array}$ & 70 & 70 & 69 & Off & Waspada \\
\hline
\end{tabular}
pengujian MCP pada tabel 4.4.

Tabel 4.3 Hasil pengujian sensor 


\begin{tabular}{|c|c|c|c|c|c|c|c|c|}
\hline & 1 & & & & & & & Ketika sensor DS18B20 mengalami \\
\hline 5 & $\begin{array}{c}8-3- \\
202 \\
1\end{array}$ & $\begin{array}{l}8 \\
0\end{array}$ & $\begin{array}{c}80 . \\
5\end{array}$ & $\begin{array}{l}80 . \\
75\end{array}$ & 77 & Off & Siaga & $\begin{array}{l}\text { ganguan sensor secara otomatis menampilkan } \\
\text { nilai }-127 \text { dan untuk mengantisipasi hal } \\
\text { tersebut, alat ini menggunakan tombol virtual }\end{array}$ \\
\hline 6 & $\begin{array}{c}8-3- \\
202 \\
1\end{array}$ & $\begin{array}{l}9 \\
0\end{array}$ & 91 & 91 & 84 & Off & Siaga & $\begin{array}{l}\text { pada platform blynk sebagai syarat untuk } \\
\text { pembacaan suhu ketika tombol virtual dalam } \\
\text { keadaan aktif sensor akan membaca suhu }\end{array}$ \\
\hline 7 & $\begin{array}{c}8-3- \\
202 \\
1\end{array}$ & $\begin{array}{l}1 \\
0 \\
0\end{array}$ & $\begin{array}{c}98 . \\
75\end{array}$ & 98 & 95 & On & Bahaya & $\begin{array}{l}\text { secara manual sebaliknya ketika tombol } \\
\text { virtual dala keadaan tidak aktif maka data } \\
\text { yang tampil berupa "off". }\end{array}$ \\
\hline
\end{tabular}

Tabel 4.4 Hasil pengujian MCP

\subsection{Pembahasan}

Monitoring kenaikan suhu pada transformer berbasis IoT merupakan sebuah inovasi pengembangan teknologi dalam bidang proteksi kebakaran khususnya pada industri pembangkit listrik maupun distribusi listrik dimana kedua sensor DS18B20 akan diletakan pada sisi atas dan bawah transformer kemudian sensor mendeteksi kenaikan suhu dan akan terbaca oleh modul ESP32 melalui pin digital kemudian data sensor akan dikirimkan ke cloud internet secara realtime agar dapat terakses oleh platform IoT Blynk pada android.

Cara pembacaan suhu sensor DS18B20 ialah dengan menempelkan sensor pada sebuah media panas yang akan diukur, kemudian dengan memanfaatkan sifat kalor pada media tersebut sensor akan mendapatkan suhu yang sama dengan media tersebut setelah itu data akan diolah oleh mikrokontroler untuk ditampilkan. Dalam kasus ini peneliti memiliki 4 kelasifikasi yaitu normal, siaga, waspada dan bahaya, hanya dalam konsdisi bahaya mikrokontroler memerintahkan sirine untuk aktif.
Alat ini juga di lengkapi dengan MCP

\begin{tabular}{|c|c|c|c|c|}
\hline No & $\begin{array}{c}\text { Mannual } \\
\text { Call Point }\end{array}$ & $\begin{array}{c}\text { Serial } \\
\text { Monitor }\end{array}$ & $\begin{array}{c}\text { Output } \\
\text { Alarm }\end{array}$ & Notifikasi \\
\hline 1 & $\begin{array}{c}\text { Tidak } \\
\text { ditekan }\end{array}$ & 1 & Off & $\begin{array}{c}\text { MCP Tidak } \\
\text { Aktif }\end{array}$ \\
\hline 2 & Ditekan & 0 & On & MCP Aktif \\
\hline
\end{tabular}

(manual call point) yang berguna untuk memberikan infomasi darurat ke mikrokontroler secara manual untuk menghindari adanya hal - hal yang tidak dapat terdeteksi oleh sensor misalnya munculnya api yang belum begitu besar. Ketika MCP ditekan mikrokontroler akan mengirimkan notifikasi serta menyalakan sirine tanpa memperdulikan nilai suhu kedua sensor DS18B20.

Kecepatan pengiriman data suhu ke platform blynk pada android tegantung pada kecepatan internet server yang digunakan. Platform blynk pada android juga dilengkapi fitur grafik, nilai, gauge dan data yang di tampilkan akan terekam dan dapat di kirimkan pada email yang terdaftar pada platform blynk.

\section{Grafik Hasil Pengukuran}




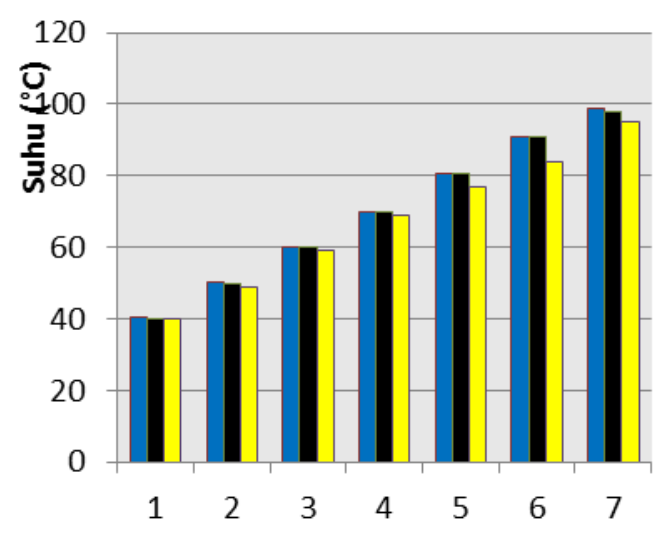

Suhu Low Side $\left({ }^{\circ} \mathrm{C}\right)$ - Suhu Up Side $\left({ }^{\circ} \mathrm{C}\right)$

$\square$ Alat Ukur $\left({ }^{\circ} \mathrm{C}\right)$

Gambar 7. Grafik data hasil monitoring kanaikan suhu oleh sensor dan alat ukur

Dari data pada gambar grafik diatas terlihat bahwa nilai suhu ( $\left.{ }^{\circ} \mathrm{C}\right)$ memiliki selisih yang tinggi terjadi pada pengujian ke tujuh degan selisih \pm 3 derajat dan selisih terendah pada pengujian pertama \pm 0.5 derajat sedangkan pada pengujian kedua sampai ke empat memiliki nilai selisih yang stabil \pm 1 derajat. Pengujian dilakukan mengambil nilai data secara realtime selisih juga terjadi antara kedua sensor DS18B20 yaitu 0.25 derajat.

\section{Kesimpulan}

Dari data hasil perancangan dan penelitian yang telah dilakukan pada tugas akhir yang berjudul sistem monitoring kenaikan suhu pada transformer berbasis IoT maka diperoleh kesmpulan sebagai berikut :

1. Dengan adanya alat sistem monitoring kenaikan suhu pada transformer berbasis IoT ini diharapkan dapat menjadi rujukan dalam merancang alat yang mempermudah para tenaga pekerja dalam memonitoring suhu transformer.

2. Cara menghubungkan antara smartphone dan alat ini menggunakan koneksi internet dimana untuk menghubungkannya melalui kode alamat aplikasi yang diberikan oleh blynk melalui email kemudian mikrokontroler akan memproses data sensor setelah itu notifikasi dikirimkan melalui internet sesuai dengan alamat yang ditunjukkan.

3. Tampilan data pada android berbentuk tampilan gauge dan grafik sehingga dapat menunjukan hasil pengukuran secara realtime maupun yang sebelumnya. Serta dapat mengontrol aktifitas sensor ketika terjadi masalah.

\section{Daftar Pustaka}

[1] Sumardi, S., Putra, I.S. 2018. Rancang Bangun Monitoring Ketinggian Air dan Sistem Control Pada Pintu Air Berbasis Arduino Dan SMS Gateway, Program Studi Teknik Sipil, Universitas Muhammadiyah Tangerang, Banten

[2] Anonim. 2021. Definisi Fire Alarm System, https://mumtazku.co.id/pengertianalarm-system/, diakses : 28 Agustus 2020 
[3] Burange, A.W., Misalkar. H.D., 2015.Review of Internet of Things in Development of Smart Cities with Data Management \& Privacy.

[4] Pratiwi, R.2017. Software Arduino IDE, http://electronicsoftware. co.id/2017/05/01/tutorial-ArduinoIDE . Diakses : 1 Maret 2020.

[5] Laboratory, N. 2021 Tutorial Menggunakan Sensor Suhu DS18B20 Pada Arduino, https://tutorkeren.com/, diakses: 22 Mei 2021

[6] Anonim. 2014. Cara Kerja Break Glass Pada Manual Call Point, https://www.bromindo.com/, diakses: 10 agustus 2020

[7] Artiyasa, M. 2020. Studi Perbandingan Platform Internet of Things (IoT) untuk Smart Home dengan aplikasi Web Thingspeak dan Blynk, Teknik Elektro, Universitas Nusa Putra, Sukabumi 